\title{
RAPD analysis of genetic diversity and population structure of Elymus sibiricus (Poaceae) native to the southeastern Qinghai-Tibet Plateau, China
}

\author{
X. Ma' ${ }^{1}$, S.-Y. Chen ${ }^{1}$, S.-Q. Bai ${ }^{1,2}$, X.-Q. Zhang ${ }^{1}$, D.-X. Li' ${ }^{2}$, C.-B. Zhang ${ }^{2}$ \\ and J.-J. Yan' \\ ${ }^{1}$ Department of Grassland Science, Animal Science and Technology College, \\ Sichuan Agricultural University, Ya'an, Sichuan, P.R. China \\ ${ }^{2}$ Sichuan Academy of Grassland Science, Chengdu, Sichuan, P.R. China \\ Corresponding author: S.-Q. Bai \\ E-mail: baiturf@yahoo.com.cn
}

Genet. Mol. Res. 11 (3): 2708-2718 (2012)

Received January 27, 2012

Accepted May 14, 2012

Published June 27, 2012

DOI http://dx.doi.org/10.4238/2012.June.27.5

\begin{abstract}
Genetic diversity of Elymus sibiricus (Poaceae) was examined in eight populations from the southeast Qinghai-Tibet Plateau. We detected 291 RAPD polymorphic loci in 93 samples. The percentage of polymorphic bands $(P P B)$ was $79 \%$. Genetic diversity $\left(H_{\mathrm{E}}\right)$ was 0.264 , effective number of alleles $\left(N_{\mathrm{E}}\right)$ was 1.444, Shannon's information index $\left(H_{\mathrm{o}}\right)$ was 0.398 , and expected Bayesian heterozygosity $\left(H_{\mathrm{B}}\right)$ was 0.371 . At the population level, $P P B=51 \%, N_{\mathrm{E}}=1.306, H_{\mathrm{E}}=0.176, I=0.263$, and $H_{\mathrm{B}}=0.247$. A high level of genetic differentiation was detected based on Nei's genetic diversity analysis $\left(G_{\mathrm{ST}}=32.0 \%\right)$, Shannon's index analysis $(33.7 \%)$, and the Bayesian method $\left(\theta_{\mathrm{B}}=33.5 \%\right)$. The partitioning of molecular variance by AMOVA demonstrated significant genetic differentiation within populations $(60 \%)$ and among populations $(40 \%)$. The average number of individuals exchanged between
\end{abstract}


populations per generation $\left(N_{\mathrm{m}}\right)$ was 1.06 . The populations were found to share high levels of genetic identity. No significant correlation was found between geographic distance and pairwise genetic distance $(r=0.7539, \mathrm{P}=0.9996)$. Correlation analysis revealed a significant correlation $(\mathrm{r}=0.762)$ between RAPD $H_{\mathrm{E}}$ found in this study and ISSR $H_{\mathrm{E}}$ values from a previous study.

Key words: Elymus sibiricus; RAPDs; Genetic diversity; Population structure

\section{INTRODUCTION}

Elymus L. is the largest and most widely distributed genus in the grass tribe Triticeae (Poaceae) with about 150 polyploid species occurring in most temperate regions of the world (Dewey, 1984). It is related to three of the most important cereal crops, i.e., wheat, barley and rye, as well as several valuable forage grasses. The genus possesses many valuable qualities, such as wide adaptation range, stress tolerance, disease resistance, apomixis, and good forage quality. Hence, it attracts considerable interest for the improvement of the cereal crops and forage breeding (McGuire and Dvorak, 1981; Dewey, 1984). The great ecological importance of Elymus species for revegetation, soil stabilization and erosion control has also been recognized (Knapp and Rice, 1996). E. sibiricus L. (Siberian wildrye), the type species of the genus Elymus, is a perennial, selfpollinating and allotetraploid grass indigenous to Northern Eurasia, possessing the St and $\mathrm{H}$ genome (Dewey, 1974). Its natural geographic distribution extends from Sweden to Japan and even to parts of Alaska and Canada (Bowden and Cody, 1961), and it extends south to Qinghai-Tibet Plateau, which is the highest plateau in the world. This plateau occupies an area of about 2,500,000 square kilometers and is characterized by harsh and diverse ecological conditions, such as drought, cold temperatures, strong winds, and high radiation. E. sibiricus usually grows on wet meadows, riverside sands, and among open forest or shrubs. In the subalpine meadows with less than $4000 \mathrm{~m}$ a.s.l. in Qinghai-Tibet Plateau, E. sibiricus usually serves as an important forage species. Climate warming, loss of habitat by deforestation and overgrazing at high altitude pastures in the entire QinghaiTibet Plateau region have now led to the recent decline of the species.

A good understanding of the current status of genetic diversity and the adaptive potential of populations is a prerequisite for the successful management of conservation programs. Applying the appropriate degree of caution, random amplified polymorphic DNA (RAPD) markers (Williams et al., 1990) can provide invaluable tools to study patterns of genetic variability due to their advantages over other molecular methods, such as less complex and laborintensive procedures and more arbitrary sampling of the genome. Until now, RAPD technology has fast become a means of investigating genetic diversity within and between populations and has been applied to many grasses.

The objectives of the present study were 1) to investigate the level of RAPD variation in eight natural populations of E. sibiricus in southeast Qinghai-Tibet Plateau, 2) to quantify the genetic diversity within and between natural E. sibiricus populations (such information can also serve as a guide to preserving the genetic resources of this ecologi- 
cally important species), and 3) to examine the consistency of results from RAPD and ISSR variation previously carried out in E. sibiricus (Ma et al., 2008).

\section{MATERIAL AND METHODS}

\section{Plant material and RAPD amplification}

Eight natural populations of E. sibiricus L. were sampled in the southeastern part of Qinghai-Tibet Plateau in China (Table 1). Individual blades generally 5-10 m apart from one another were sampled randomly to assure that they were different individuals. Vouchers of the materials used are kept at Sichuan Academy of Grassland Science, China. The leaf tissues were stored at $-20^{\circ} \mathrm{C}$ until DNA extraction. Purity and concentration of the genomic DNA were determined with a spectrophotometer (Nanodrop).

Table 1. Location, population size, and altitude in each study site.
\begin{tabular}{llcccc}
\hline Population & Locality & Sample size & Altitude (m) & Latitude (N) & Longitude (E) \\
\hline POP1 & Wengda of Seda, Sichuan & 10 & 3344 & $31^{\circ} 52^{\prime}$ & $100^{\circ} 43^{\prime}$ \\
POP2 & Xuri of Seda, Sichuan & 8 & 3567 & $31^{\circ} 59^{\prime}$ & $100^{\circ} 36^{\prime}$ \\
POP3 & Litang, Sichuan & 11 & 3673 & $30^{\circ} 18^{\prime}$ & $100^{\circ} 17^{\prime}$ \\
POP4 & Yajiang, Sichuan & 18 & 3525 & $30^{\circ} 02^{\prime}$ & $101^{\circ} 17^{\prime}$ \\
POP5 & Songpan, Sichuan & 9 & 3214 & $32^{\circ} 53^{\prime}$ & $103^{\circ} 29^{\prime}$ \\
POP6 & Aba, Sichuan & 10 & 3324 & $32^{\circ} 45^{\prime}$ & $102^{\circ} 03^{\prime}$ \\
POP7 & Rangtang, Sichuan & 12 & 3362 & $32^{\circ} 26^{\prime}$ & $32^{\circ} 02^{\prime}$ \\
POP8 & Hongyuan, Sichuan & 15 & 3414 & $32^{\circ} 05^{\prime}$ & $102^{\circ} 34^{\prime}$ \\
\hline
\end{tabular}

Amplification reactions were performed based on the standard protocol of Williams et al. (1990) with some modifications. PCR mixtures $(20 \mu \mathrm{L})$ contained $20 \mathrm{ng}$ template DNA, $0.2 \mathrm{mM}$ each dNTP, $2.5 \mathrm{mM} \mathrm{MgCl}_{2}, 1.0 \mathrm{U}$ Taq polymerase (Tiangen Biotech Co., Ltd., Beijing, China), 15 pmol of a single 10-mer primer purchased from Operon Technologies (Alameda, CA, USA), and UBC (University of British Columbia, Vancouver, BC, Canada). The amplification was performed in a PTC-200 thermocycler (MJ Research, Waltham MA, USA). Initial denaturation was for 2 min at $94^{\circ} \mathrm{C}$, followed by 42 cycles of $1 \mathrm{~min}$ at $94^{\circ} \mathrm{C}, 1 \mathrm{~min}$ at $35^{\circ} \mathrm{C}$, and $2 \mathrm{~min}$ at $72^{\circ} \mathrm{C}$, with a final extension of $5 \mathrm{~min}$ at $72^{\circ} \mathrm{C}$. The amplification products were separated via electrophoresis on $1.5 \%$ agarose gels (containing $0.1 \mathrm{mg} / \mathrm{mL}$ ethidium bromide) with $0.5 \mathrm{X}$ TBE buffer. The gels were then observed and photographed under ultraviolet light.

\section{Data analysis}

Only bands that could be unambiguously scored were used in subsequent analyses. RAPD profiles were determined for each individual based on the presence (1) or absence $(0)$ of specific bands. The following genetic diversity parameters were calculated: $N_{\mathrm{p}}$ (number of polymorphic loci), $P P B$ (percentage of polymorphic loci), $N_{\mathrm{E}}$ (effective number of alleles per locus), $N_{\mathrm{O}}$ (observed number of alleles per locus), and $H_{\mathrm{E}}$ (Nei's gene diversity). At the species-wide level, total genetic diversity $\left(H_{\mathrm{t}}\right)$, genetic diversity within populations $\left(H_{\mathrm{s}}\right)$ and Nei's genetic differentiation between populations $\left(G_{\mathrm{ST}}\right)$ were 
calculated (Nei, 1973). The number of immigrants per generation $\left(N_{\mathrm{m}}\right)$ was measured by the formula: $N_{\mathrm{m}}=0.5\left(1-G_{\mathrm{ST}} / G_{\mathrm{ST}}(\right.$ McDermott and McDonald, 1993). All the above calculations were performed with the assistance of PopGene version 1.31 (Yeh et al., 1997). The PopGene software was also used to calculate Shannon's diversity index for RAPD phenotypic data according to $I=-\Sigma p_{\mathrm{i}} \log _{2} p_{\mathrm{i}}$ (Lewontin, 1972), in which $p_{\mathrm{i}}$ is the frequency of a given RAPD fragment. $H_{\mathrm{O}}$ was calculated at two levels: the average diversity within populations $\left(I_{\text {pop }}\right)$, and the total diversity $\left(I_{\mathrm{sp}}\right)$. The proportion of diversity between populations was estimated as $\left(I_{\mathrm{sp}}-I_{\mathrm{pop}}\right) / I_{\mathrm{sp}}$. For the calculation of $H_{\mathrm{E}}, G_{\mathrm{ST}}, N_{\mathrm{m}}$, and $N_{\mathrm{E}}$, allele frequencies were based on the square root of the frequency of the null (recessive) allele. Given that the above estimation of allele frequencies from dominant markers requires the assumption of Hardy-Weinberg equilibrium (HWE), within-population gene diversity was also estimated using a Bayesian approach $\left(H_{\mathrm{B}}\right)$, employing the Hickory, version 1.1 program (Holsinger and Lewis, 2007).

To study the partitioning of genetic variance between populations, we conducted an analysis of molecular variance (AMOVA) by using the Arlequin version 3.11 program (Excoffier et al., 2005). Variance components, the sum of all squared differences, and analogues of $F$-statistics ( $\left.\Phi_{\mathrm{ST}}\right)$ based on Euclidean distance between individuals were calculated to estimate the population differentiation, which is the equivalent of the Wright's $F_{\text {ST }}$ index (Wright, 1965). In addition, a matrix of Nei's unbiased genetic distance (Nei, 1978) was calculated between all pairs of populations and subjected to UPGMA clustering as implemented in TFPGA version 1.3 (Miller, 1997). Bootstrap values were obtained by resampling with replacement over loci (1000 replicates). To test the hypothesis of isolation by distance, the correlation between pairwise geographic and Nei's genetic distances was tested for all natural populations by using the Mantel test with 3000 permutations (Mantel, 1967). In addition, the computation of the Spearman rank correlation between RAPD gene diversity $\left(H_{\mathrm{E}}\right)$ values obtained in this study and ISSR $H_{\mathrm{E}}$ values obtained previously (Ma et al., 2008) was carried out with SAS 8.0.

\section{RESULTS}

\section{Genetic diversity within populations}

The survey of 93 individuals from eight populations of E. sibiricus with 25 RAPD primers generated a total of 370 fragments, 291 (78.65\%) of which were polymorphic (Table 2). The band sizes ranged from 300 to $2500 \mathrm{bp}$. Band number per primer ranged from 6 to 28, corresponding to an average of 14.8 bands per primer. All individuals tested produced different RAPD profiles. Levels of RAPD variation within populations varied moderately across populations (Table 3 ). Assuming HWE, the average gene diversity $\left(H_{\mathrm{E}}\right)$ ranged from 0.159 (POP5) to 0.190 (POP6) for E. sibiricus, with an average of $0.176 \pm$ 0.012 at the population level. The Shannon's index (I) ranged from 0.173 to 0.284 , with an average of $0.263 \pm 0.018$ at the population level. Among these eight populations, POP6 and POP4 exhibited the greatest level of variability $\left(P P B=53.78\right.$ and $52.43 \%, N_{\mathrm{E}} 1.324$ and $1.329, H_{\mathrm{E}}=0.190$ and $0.187, I=0.284$ and 0.277 , and $H_{\mathrm{B}}=0.269$ and 0.255 , respectively). By contrast, genetic diversity was lowest in population POP5, with $P P B=46.49 \%, N_{\mathrm{E}}=$ $1.281, H_{\mathrm{E}}=0.159, I=0.173$, and $H_{\mathrm{B}}=0.213$ (Table 3). 
ISSR analysis had been previously performed on these populations (Ma et al., 2008) and used in this study. Consequently, the genetic diversity profiles obtained in this study with RAPD markers can be compared with those obtained previously with ISSR markers. The average RAPD values for $P_{\mathrm{P}}$ and $H_{\mathrm{E}}$ were 0.512 (ranging from 0.465 to 0.535 ) and 0.176 (ranging from 0.159 to 0.190 ), as compared to the ISSR values of 0.507 (ranging from 0.440 to 0.549 ) and 0.181 (ranging from 0.164 to 0.200 ), respectively. The correlation between RAPD and ISSR gene diversity $\left(H_{\mathrm{E}}\right)$ values was relatively high $(\mathrm{r}=$ $0.762, \mathrm{P}=0.028$ ) (Figure 1).

\section{Table 2. Polymorphism of RAPD bands amplified by the 25 RAPD primers.}

\begin{tabular}{|c|c|c|c|}
\hline Primer code & Sequence $\left(5^{\prime} \rightarrow 3^{\prime}\right)$ & No. of bands scored & No. of polymorphic bands \\
\hline OPA-06 & GGTCCCTGAC & 19 & 16 \\
\hline OPA-11 & CAATCGCCGT & 27 & 22 \\
\hline OPA-12 & TCGGCGATAG & 18 & 14 \\
\hline OPA-14 & TCTGTGCTGG & 11 & 7 \\
\hline OPA-16 & AGCCAGCGAA & 8 & 5 \\
\hline OPB-02 & TGATCCCTGG & 28 & 19 \\
\hline OPB-03 & CATCCCCCTG & 18 & 14 \\
\hline OPB-04 & GGACTGGAGT & 21 & 19 \\
\hline OPB-05 & TGCGCCCTTC & 24 & 19 \\
\hline OPB-06 & TGCTCTGCCC & 12 & 10 \\
\hline OPB-08 & GTCCACACGG & 24 & 22 \\
\hline OPB-15 & GGAGGGTGTT & 12 & 10 \\
\hline OPB-19 & ACCCCCGAAG & 18 & 17 \\
\hline OPD-01 & ACCGCGAAGG & 17 & 12 \\
\hline OPF-14 & TGCTGCAGGT & 12 & 10 \\
\hline OPF-15 & CCAGTACTCC & 16 & 14 \\
\hline OPG-06 & GTGCCTAACC & 6 & 5 \\
\hline OPG-09 & CTGACGTCAC & 11 & 8 \\
\hline OPM-19 & CCTTCAGGCA & 13 & 9 \\
\hline OPR-05 & GACCTAGTGG & 9 & 8 \\
\hline UBC106 & CGTCTGCCCG & 14 & 10 \\
\hline UBC119 & ATTGGGCGAT & 6 & 3 \\
\hline UBC120 & GAATTTCCCC & 7 & 6 \\
\hline UBC121 & ATACAGGGAG & 12 & 7 \\
\hline UBC 150 & GAAGGCTCTG & 7 & 5 \\
\hline Total & & 370 & 291 \\
\hline Mean & & 14.8 & 11.6 \\
\hline
\end{tabular}

\begin{tabular}{|c|c|c|c|c|c|c|c|}
\hline Population & $N_{\mathrm{p}}$ & $P P B(\%)$ & $N_{\mathrm{O}}$ & $N_{\mathrm{E}}$ & $I$ & $H_{\mathrm{E}}$ & $H_{\mathrm{B}}$ \\
\hline POP1 & 198 & 53.51 & 1.535 & 1.315 & 0.275 & 0.183 & 0.254 \\
\hline POP2 & 187 & 50.54 & 1.505 & 1.298 & 0.237 & 0.175 & 0.253 \\
\hline POP3 & 181 & 48.92 & 1.489 & 1.278 & 0.239 & 0.160 & 0.223 \\
\hline POP4 & 194 & 52.43 & 1.524 & 1.329 & 0.277 & 0.187 & 0.255 \\
\hline POP5 & 172 & 46.49 & 1.465 & 1.281 & 0.173 & 0.159 & 0.213 \\
\hline POP6 & 199 & 53.78 & 1.539 & 1.324 & 0.284 & 0.190 & 0.269 \\
\hline POP7 & 194 & 52.43 & 1.524 & 1.328 & 0.276 & 0.186 & 0.254 \\
\hline POP8 & 190 & 51.35 & 1.514 & 1.296 & 0.261 & 0.173 & 0.255 \\
\hline Average & 189 & 51.18 & 1.512 & 1.306 & 0.263 & 0.176 & 0.247 \\
\hline Species & 291 & 78.65 & 1.787 & 1.444 & 0.398 & 0.264 & 0.371 \\
\hline
\end{tabular}

$N_{\mathrm{p}}=$ polymorphic loci; $P P B=$ percentage of polymorphic loci; $N_{\mathrm{O}}=$ number of alleles per locus; $N_{\mathrm{E}}=$ effective number of alleles per locus; $I=$ Shannon's information index; $H_{\mathrm{E}}=$ Nei's (1973) measure of gene diversity; $H_{\mathrm{B}}=$ expected Bayesian heterozygosity (without assuming Hardy-Weinberg equilibrium). 


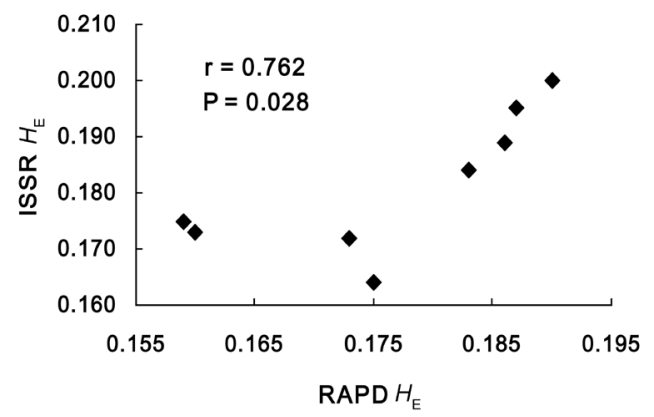

Figure 1. Spearman's rank correlation between the genetic diversity $\left(H_{\mathrm{E}}\right)$ values produced by random amplified polymorphic DNA (RAPD) analysis from this study and inter-simple sequence repet (ISSR) analysis from previous study (Ma et al., 2008).

\section{Population structure of RAPD variation}

Across the eight populations of E. sibiricus surveyed for RAPD variation, Nei's (1973) estimator of population substructure $\left(G_{\mathrm{ST}}\right)$ indicated a relatively high level of population differentiation $\left(G_{\mathrm{ST}}=0.320\right)$. These $G_{\mathrm{ST}}$ values translated into correspondingly low levels of gene flow $\left(N_{\mathrm{m}}\right)$, with 1.06 migrants exchanged between populations (on average) each generation. The Shannon's index partitioned $33.7 \%$ of the total variation between populations, in broad agreement with the result of genetic differentiation analysis. Population differentiation $\left(\theta_{\mathrm{B}}\right)$ values were obtained using three Bayesian models. The full model yielded the smallest DIC value (7061.35), which suggests that this model is the best suited of the three population differentiation models examined. The value of $\theta_{\mathrm{B}}$ was 0.35 , similar to the value of $G_{\mathrm{ST}}$ based on an assumption of HWE. AMOVA also revealed highly significant genetic differences between the eight populations of $E$. sibiricus. Of the total genetic diversity, $40.05 \%$ of the variance occurred between populations $\left(\Phi_{\mathrm{ST}}=0.401, \mathrm{P}<0.001\right)$ and $59.95 \%$ occurred between individuals within populations (Table 4). When these populations were included into two groups (south and north) according to sampling sites, the variance between populations within the groups was $11.18 \%$, whereas the variance between groups was $41.40 \%$. A highly significant $(\mathrm{P}<0.001)$ genetic difference was found between groups, between populations, and within populations.

Table 4. AMOVA results generated within Elymus sibiricus populations and geographic groups.

\begin{tabular}{lrcccc}
\hline Source of variation & d.f. & Sum of squares & Variance component & Total variance & P value \\
\hline Among populations & 7 & 2136.09 & 23.47 & $40.05 \%$ & $<0.001$ \\
Within populations & 85 & 2985.72 & 35.13 & $59.95 \%$ & $<0.001$ \\
Among groups (south and north) & 1 & 1374.96 & 30.66 & $41.40 \%$ & $<0.001$ \\
Among populations/groups & 6 & 761.13 & 8.28 & $11.18 \%$ & $<0.001$ \\
Within populations & 85 & 2985.72 & 35.13 & $47.43 \%$ & $<0.001$ \\
\hline
\end{tabular}

d.f. $=$ degrees of freedom.

\section{Phylogenetic relationship}

Estimates of genetic distance (D, Nei's measure) between pairs of populations were calculated based on 149 markers scored (Table 5). Values ranged from 0.0163 (between POP1 and POP2) to 0.3036 (between POP6 and POP4) with an average of 0.1458 . The average of 
genetic identity (I) was 0.8689 . A UPGMA tree (Figure 2) based on Nei's unbiased genetic distance of all populations suggested that POP3 and POP4 in the southern sampling sites comprised a distinct group, while the remaining six from the northern sampling sites formed another cluster. However, no significant correlation was found between geographic distance and pairwise genetic distance $(\mathrm{r}=0.7539, \mathrm{P}=0.9996)$ based on the Mantel test. This indicates that there is no clear geographic tendency in the distribution of genetic variability, i.e., an "isolation by distance" model was not supported.

Table 5. Estimates of Nei’s (1978) unbiased genetic distance among Elymus sibiricus populations.

\begin{tabular}{lccccccc}
\hline Population & POP1 & POP2 & POP3 & POP4 & POP5 & POP6 & POP7 \\
\hline POP1 & 0.0000 & & & & & & \\
POP2 & 0.0163 & 0.0000 & & & & & \\
POP3 & 0.2358 & 0.1885 & 0.0000 & & & & \\
POP4 & 0.2608 & 0.2096 & 0.0579 & 0.0000 & & & \\
POP5 & 0.0807 & 0.0704 & 0.2873 & 0.3020 & 0.0000 & & 0.0000 \\
POP6 & 0.0837 & 0.0802 & 0.2892 & 0.3036 & 0.0510 & 0.000 & 0.0553 \\
POP7 & 0.0467 & 0.0457 & 0.2219 & 0.2434 & 0.0655 & 0.0484 & 0.0000 \\
POP8 & 0.0758 & 0.0706 & 0.2918 & 0.3023 & 0.0556 & 0.0435 & 0.053 \\
\hline
\end{tabular}

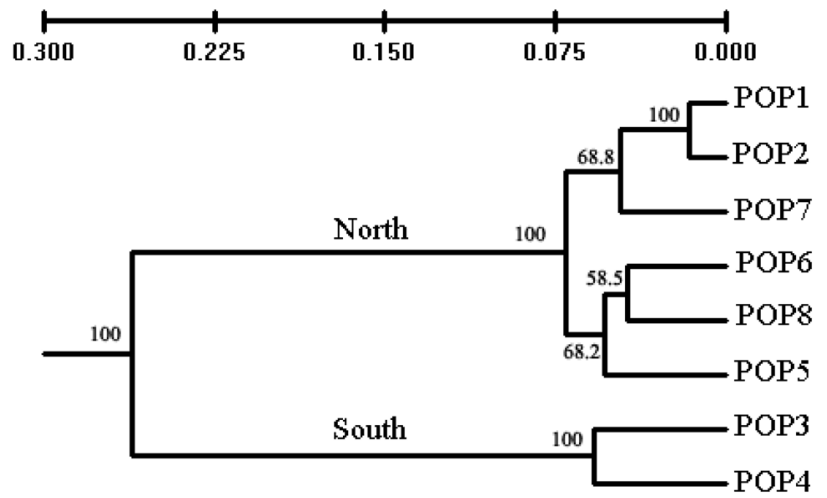

Figure 2. UPGMA phenogram illustrating the genetic relationships among eight populations of Elymus sibiricus, based on Nei's (1978) genetic distance measure calculated from 291 RAPD markers. Numbers on branches indicate bootstrap values from 1000 replicates.

\section{DISCUSSION}

\section{Genetic diversity in E. sibiricus}

The use of dominant markers to assess genetic variability between individuals and populations is promising because many polymorphic loci can be obtained fairly easily, in a relatively short time and at low cost, without any prior knowledge of the genome of the species under study (Nybom and Bartish, 2000; Nybom, 2004). In our study, the use of RAPD markers proved to be a powerful method for the detection of spatial genetic variation. With 25 primers, 
we obtained 291 polymorphic markers and could differentiate the 93 E. sibiricus individuals analyzed, reflecting a rich allelic diversity in the populations.

Genetic diversity within populations is considered to be of high importance for adaptation to changing environments and, as a consequence, for long-term survival of a species. Assessment of genetic variation is an important step towards implementing plant conservation strategies. Genetic richness can be assessed by estimating the genetic diversity parameters (the percentage of polymorphic loci and gene diversity index). In the present study, $P P B$ over eight natural populations of $E$. sibiricus was $51.2 \%$, similar to reports of RAPD variation in $E$. alaskanus (49.5\%), yet much higher than in E. fibrosus (20.3\%) (Díaz et al., 2000) and considerably lower than in E. trachycaulus (69.3\%) (Gaudett et al., 2005). In addition, Nei's gene diversity index $H_{\mathrm{E}}$ can also be associated with biological characteristics of species. Thus, if for comparison, we focus on Nei's genetic diversity, the total average of within-population RAPD diversity in E. sibiricus $\left(H_{\mathrm{E}}=0.176\right)$ is comparable to the corresponding average of RAPD diversity reported in short-lived perennial $\left(H_{\mathrm{E}}=0.20\right)$ and mixed-mating species $\left(H_{\mathrm{E}}=0.18\right)$, whereas it is slightly higher than selfers $\left(H_{\mathrm{E}}=0.12\right)$ and much lower than outcrossers $\left(H_{\mathrm{E}}=\right.$ 0.27) (Nybom, 2004). Other studies of congener species using the RAPD method have found $H_{\mathrm{E}}$ values of 0.09 in E. fibrosus (Díaz et al., 2000), 0.162 in E. alaskanus (Zhang et al., 2002), and 0.23 in E. trachycaulus (Gaudett et al., 2005). E. sibiricus has a wide distribution in temperate zones of Eurasia, especially in the relatively moist southeast area of Qinghai-Tibet Plateau. Two surveys of intra-population genetic diversity in published allozyme (Hamrick and Godt, 1996) and RAPD (Nybom, 2004) data indicated that geographically widespread plant species tend to possess higher genetic polymorphisms within populations than restrictedly distributed species. However, it should be noted that E. sibiricus populations collected for the present study originate from a narrow ecogeographic area of distribution of the species. Hence, it is necessary to investigate the genetic make-up of this species on a larger geographic scale.

The correlation analysis revealed a statistically significant correlation $(\mathrm{r}=0.762, \mathrm{P}=$ 0.028 ) between RAPD gene diversity found in this study and the ISSR gene diversity values previously obtained (Ma et al., 2008). Furthermore, other studies of related species using molecular methods found a high correlation between RAPD and microsatellite datasets in $E$. fibrosus $(\mathrm{r}=0.679)$ (Sun et al., 1998) and E. trachycaulus $(\mathrm{r}=0.799)$ (Stevens et al., 2007). The parallelism between RAPD and ISSR patterns indicates that similar and primarily deterministic (selection) evolutionary forces may be involved in shaping the genetic structure of both RAPD and ISSR loci.

\section{Genetic structure of populations}

Genetic variation is non-randomly distributed among populations, species and higher taxa (Hamrick et al., 1979). This distribution of alleles and genotypes in space or in time is often referred to as the genetic structure of a population (Loveless and Hamrick, 1984). In general, selfing species commonly have lower levels of genetic diversity and higher differentiation between populations than outcrossing plants (Schoen and Brown, 1991; Hamrick and Godt, 1996). In fact, allozyme and/or molecular marker analysis has indicated that the large proportion of variation resides at the population level for many self-pollinating Elymus species such as E. glaucus (Knapp and Rice, 1996), E. alaskanus (Díaz et al., 1999a), E. caninus (Díaz et al., 1999b), and E. fibrous (Díaz et al., 2000). However, Wilson et al. (2001) reported that 
$40 \%$ of the total allozyme variation in self-pollinating E. glaucus was detected between populations. Sun et al. (2002) detected a fairly low degree of differentiation $\left(F_{\mathrm{ST}}=0.13\right)$ among three Norwegian E. alaskanus populations using microsatellite markers. Gaudett et al. (2005) found that $31 \%$ of the total RAPD variation resided between four E. trachycaulus populations from British Columbia, Canada. In our study, eight populations were found to show a high level of genetic subdivision, with an estimated $G_{\mathrm{ST}}$ value of 0.320 [Nei (1978) classified $G_{\mathrm{ST}}$ $<0.05$ as low, $0.05-0.15$ medium, and $>0.15$ high]. There is a considerable amount of genetic differentiation among E. sibiricus populations from southeast Qinghai-Tibet Plateau. Different analyses of the RAPD data all show a high between-population variation (AMOVA, $\Phi_{\mathrm{ST}}$ $=0.401$; Nei's genetic diversity, $G_{\mathrm{ST}}=0.320$; Bayesian analysis, $\theta_{\mathrm{B}}=0.335$; Shannon's index, $\left.\left(I_{\mathrm{sp}}-I_{\mathrm{pop}}\right) / I_{\mathrm{sp}}=0.337\right)$. The AMOVA-derived $G_{\mathrm{ST}}$ analog, $\Phi_{\mathrm{ST}}$, is of comparable magnitude, 0.401 . This value is comparable to the average reported in the RAPD literature for species with short-lived perennials $\left(\Phi_{\mathrm{ST}}=0.41\right)$ as well as mixed-mating $\left(\Phi_{\mathrm{ST}}=0.40\right)$, but is still lower than generally found in predominant selfers $\left(\Phi_{\mathrm{ST}}=0.65\right)$ in a survey based on the analysis of numerous RAPD studies (Nybom, 2004).

Although no analysis of the actual self-pollinating rate of E. sibiricus has been reported, taken together with field studies, our analytical results partly suggest that $E$. sibiricus is a self-pollinating species with a relatively high outcrossing rate. Central populations of widespread species may inhabit a variety of habitats and could be more variable than marginal populations (Bantock and Price, 1975; Shumaker and Babble, 1980). Owing to the fact that the eight population studied are closely located, the possible explanation for the higher intrapopulation variation patterns revealed in this study is that these populations were collected from near the central or founding population, similar to studies on E. fibrosus (Díaz et al., 2000) and E. trachycaulus (Gaudett et al., 2005).

The $G_{\mathrm{ST}}$-derived $N_{\mathrm{m}}$ value of 1.061 is indicative of considerable gene flow between natural populations, and this value is slightly above the level $\left(N_{\mathrm{m}} \approx 1\right)$ needed to counteract genetic drift (Slatkin, 1987). The high $N_{\mathrm{m}}$ value is probably attributed to the smaller adjacent range of sampling and the similar ecogeographic environment with frequent wind for the populations studied. Because most of the collection sites were located on the sides of the highway, gene flow between populations could be promoted by human activities over long periods. Additionally, since E. sibiricus plants are perennials, recent genetic isolation and small population sizes may not have significantly affected genetic diversity.

The genetic relationships between populations of a species do not often agree with their geographic distance, especially for species with a large distribution area (Díaz et al., 1999a; Qiu et al., 2004). The same pattern also occurred in E.sibiricus. Although cluster analysis demonstrated that most populations clustered in accordance with the geographic distribution of populations, POP6 was not close to POP7, regardless of the small geographic distance between them. This pattern was also supported by the AMOVA, which showed that only $11.18 \%$ of the total variation could be accounted for by differences between populations within geographic groups (south and north) (Table 4). In addition, the Mantel test also showed that there was no significant correlation $(\mathrm{r}=0.7539, \mathrm{P}=0.9996)$ between the geographic distance matrix and the pairwise genetic distance matrix.

In short, our results indicate that RAPD is a useful and efficient tool to detect the genetic variability in Elymus sibiticus, which is similar and comparable to ISSR analysis previously performed. 


\section{ACKNOWLEDGMENTS}

Research supported by the National Key Technology Research and Development Program of China (\#2011BAD17B03), the National Science Foundation of China (\#31101763), and the Sichuan Provincial Technology Research and Development Program, China (\#2011ZC0113).

\section{REFERENCES}

Bantock CR and Price DJ (1975). Marginal populations of Cepaea nemoralis (L.) on the Brenden Hills, England. I. Ecology and ecogenetics. Evolution 29: 267-277.

Bowden WM and Cody WJ (1961). Recognition of Elymus sibiricus L. from alaska and the district of mackenzie. Bull. Torrey Bot. Club 88: 153-155.

Dewey DR (1974). Cytogenetics of Elymus sibiricus and its hybrids with Agropyron tauri, Elymus canadensis, and Agropyron caninum. Bot. Gaz. 135: 80-87.

Dewey DR (1984). The Genomic System of Classification as a Guide to Intergeneric Hybridization With the Perennial Triticeae. In: Gene Manipulation in Plant Improvement (Gustafson JP, ed.). Plenum Press, New York, 209-279.

Díaz O, Salomon B and Von Bothmer R (1999a). Genetic variation and differentiation in nordic populations of Elymus alaskanus (Scrib. ex Merr.) Love (Poaceae). Theor. Appl. Genet. 99: 210-217.

Díaz O, Salomon B and Von Bothmer R (1999b). Genetic diversity and structure in populations of Elymus caninus (L.) L. (Poaceae). Hereditas 131: 63-74.

Díaz O, Sun GL, Salomon B and Von Bothmer R (2000). Levels and distribution of allozyme and RAPD variation in populations of Elymus fibrosis (Schrenk) Tzvel.(Poaceae). Genet. Res. Crop Evol. 47: 11-24.

Excoffier L, Laval G and Schneider S (2005). Arlequin ver. 3.0: An integrated software package for population genetics data analysis. Evol. Bioinform. Online 1: 47-50.

Gaudett M, Salomon B and Sun G (2005). Molecular variation and population structure in Elymus trachycaulus and comparison with its morphologically similar E. alaskanus. Plant Syst. Evol. 250: 81-91.

Hamrick JL and Godt MJW (1996). Conservation Genetics of Endemic Plant Species. In: Conservation Genetics, Case Histories from Nature (Avise JC and Hamrick JL, eds.). Chapman and Hall Press, New York, 281-304.

Hamrick JL, Linhart YB and Mitton JB (1979). Relationships between life history characteristics and electrophoretically detectable genetic variation in plants. Rev. Ecol. Syst. 10: 173-200.

Holsinger KE and Lewis PO (2007). Hickory: A Package for Analysis of Population Genetic Data. Version 1.1. Available at [http://darwin.eeb.uconn.edu/hickory/software.html]. Accessed February 15, 2010.

Knapp EE and Rice KJ (1996). Genetic structure and gene flow in Elymus glaucus (blue wildrye): implications for native grassland restoration. Restor. Ecol. 4: 1-10.

Lewontin RC (1972). The apportionment of human diversity. Evol. Biol. 6: 381-398.

Loveless MD and Hamrick JL (1984). Ecological determinants of genetic structure in plant populations. Annu. Rev. Ecol. Syst. 15: 65-95.

Ma X, Zhang XQ, Zhou YH, Bai SQ, et al. (2008). Assessing genetic diversity of Elymus sibiricus (Poaceae: Triticeae) populations from Qinghai-Tibet Plateau by ISSR markers. Biochem. Syst. Ecol. 36: 514-522.

Mantel N (1967). The detection of disease clustering and a generalized regression approach. Cancer Res. 27: 209-220.

McDermott JM and McDonald BA (1993). Gene flow in plant pathosystems. Annu. Rev. Phytopathol. 31: 353-373.

McGuire PE and Dvorak J (1981). High salt tolerance potential in wheat grasses. Crop Sci. 21: 702-705.

Miller MP (1997). Tools for Population Genetic Analysis (TFPGA). Version 1.3. Available at [http://www. marksgeneticsoftware.net/tfpga.htm]. Accessed February 10, 2010.

Nei M (1973). Analysis of gene diversity in subdivided populations. Proc. Natl. Acad. Sci. U. S. A. 70: 3321-3323.

Nei M (1978). Estimation of average heterozygosity and genetic distance from a small number of individuals. Genetics 89: 583-590.

Nybom H (2004). Comparison of different nuclear DNA markers for estimating intraspecific genetic diversity in plants. Mol. Ecol. 13: 1143-1155.

Nybom H and Bartish IV (2000). Effects of life history traits and sampling strategies on genetic diversity estimates obtained with RAPD markers in plants. Plant Ecol. Evol. Syst. 3: 93-114.

Qiu YX, Hong DY, Fu CX and Kenneth MC (2004). Genetic variation in the endangered and endemic species Changium smyrnioides (Apiaceae). Biochem. Syst. Ecol. 32: 583-596.

Genetics and Molecular Research 11 (3): 2708-2718 (2012)

CFUNPEC-RP www.funpecrp.com.br 
Schoen DJ and Brown AH (1991). Intraspecific variation in population gene diversity and effective population size correlates with the mating system in plants. Proc. Natl. Acad. Sci. U. S. A. 88: 4494-4497.

Shumaker KM and Babble GR (1980). Patterns of allozymic similarity in ecologically central and marginal populations of Hordeum jubatum in Utah. Evolution 34: 110-116.

Slatkin M (1987). Gene flow and the geographic structure of natural populations. Science 236: 787-792.

Stevens L, Salomon B and Sun GL (2007). Microsatellite variability and heterozygote excess in Elymus trachycaulus populations from British Columbia in Canada. Biochem. Syst. Ecol. 35: 725-736.

Sun GL, Díaz O, Salomon B and Von Bothmer R (1998). Microsatellite variation and its comparison with allozyme and RAPD variation in Elymus fibrosus (Schrenk) Tzvel (Poaceae). Hereditas 129: 275-282.

Sun GL, Salomon B and Von Bothmer R (2002). Microsatellite polymorphism and genetic differentiation in three Norwegian populations of Elymus alaskanus (Poaceae). Plant Syst. Evol. 234: 101-110.

Williams JG, Kubelik AR, Livak KJ, Rafalski JA, et al. (1990). DNA polymorphisms amplified by arbitrary primers are useful as genetic markers. Nucleic Acids Res. 18: 6531-6535.

Wilson BL, Kitzmiller J, Rolle W and Hipkins VD (2001). Isozyme variation and its environmental correlates in Elymus glaucus from the California Floristic Province. Can. J. Bot. 79: 139-153.

Wright S (1965). The interpretation of population structure by F-statistics with special regard to systems of mating. Evolution 19: 395-420.

Yeh FC, Yang RC, Boyle T, Ye ZH et al. (1997). PopGene, the User Friendly Shareware for Population Genetic Analysis. Available at [http://www.ualberta.ca/ fyeh/popgene_info.html]. Accessed December 10, 2009.

Zhang XQ, Salomom B and Von Bothmer R (2002). Application of random amplified polymorphic DNA markers to evaluate intraspecific genetic variation in the Elymus alaskanus complex (Poaceae). Genet. Res. Crop Evol. 49: 399-409. 